\title{
A Persistently High End-Tidal Carbon Dioxide Value: Can This Be Spurious?
}

\author{
Barkha Bindu ${ }^{1} \quad$ Gyaninder P. Singh ${ }^{1}$ Varun Jain ${ }^{1}$ Arvind Chaturvedi ${ }^{1}$ \\ ${ }^{1}$ Department of Neuroanaesthesiology and Critical Care, \\ Neurosciences Centre, All India Institute of Medical Sciences, \\ New Delhi, India

\begin{abstract}
Address for correspondence Gyaninder P. Singh, MD, DM, Room No. 711 (7th Floor), Department of Neuroanaesthesiology and Critical Care Neurosciences Centre, All India Institute of Medical
\end{abstract} \\ Sciences, New Delhi 110029, India (e-mail: drsingh_gp@yahoo.co.in).
}

J Neuroanaesthesiol Crit Care 2020;7:104-106

\begin{abstract}
Keywords

- end-tidal carbon dioxide

- monitor malfunction

- anesthesia

- capnography

End-tidal carbon dioxide $\left(\mathrm{EtCO}_{2}\right)$ monitoring has now become the standard of care not only during anesthesia but also in intensive care units for patients on mechanical ventilation, emergency department, and pre-hospital settings to confirm and monitor the correct placement of endotracheal tube. It is a non-invasive and continuous method of measuring exhaled carbon dioxide $\left(\mathrm{CO}_{2}\right)$. Continuous waveform capnography measures $\mathrm{EtCO}_{2}$ and monitors ventilation. $\mathrm{EtCO}_{2}$ often correlates with partial pressure of carbon dioxide in arterial blood $\left(\mathrm{PaCO}_{2}\right)$ and is a reliable indicator of $\mathrm{PaCO}_{2}$. A rise in $\mathrm{EtCO}_{2}$ often implies increased production of $\mathrm{CO}_{2}$ or decreased excretion (rebreathing, decrease ventilation) of $\mathrm{CO}_{2}$. We report an unusual case where the monitor malfunction per se lead to spuriously increased $\mathrm{EtCO}_{2}$ values without any clinical cause and did not correlate with $\mathrm{PaCO}_{2}$, thereby re-emphasizing that various monitors must always be interpreted in correlation with clinical observation.
\end{abstract}

\section{Introduction}

End-tidal carbon dioxide $\left(\mathrm{EtCO}_{2}\right)$ monitoring is considered standard of care during anesthesia, in mechanically ventilated patients in intensive care unit and in pre-hospital settings to confirm correct placement of endotracheal tube (ETT). ${ }^{1}$ Apart from the advantages of being a continuous and non-invasive monitor of exhaled carbon dioxide $\left(\mathrm{CO}_{2}\right)$, it is also a reliable indicator of partial pressure of $\mathrm{CO}_{2}\left(\mathrm{PaCO}_{2}\right)$ in arterial blood and is often used as its surrogate. ${ }^{2}$ Changes in $\mathrm{EtCO}_{2}$ and $\mathrm{PaCO}_{2}$ normally parallel each other and the difference between the two is approximately 3.6 to $4.6 \mathrm{~mm}$ $\mathrm{Hg}$ in healthy awake patients. ${ }^{3}$ We report a case where $\mathrm{EtCO}_{2}$ values were disproportionately high and did not correlate with $\mathrm{PaCO}_{2}$.

\section{Case Presentation}

A 62-year-old female patient weighing $59 \mathrm{~kg}$ was diagnosed with L5-S1 listhesis and was planned for surgery. She was a known hypertensive, controlled on amlodipine ( $5 \mathrm{mg}$ daily) for last 7 years. On pre-anesthetic check-up, she had bilateral wheeze and was optimized with corticosteroid, and bronchodilator nebulization for 1 week before surgery. Her preoperative investigations including pulmonary function tests were within normal limits. In the operating room, peripheral intravenous access was established, and routine standard monitoring was started (electrocardiography, non-invasive blood pressure, pulse-oximeter, and sidestream capnography). After preoxygenation with $100 \%$ oxygen for 3 minutes, general anesthesia was induced with intravenous fentanyl $120 \mu \mathrm{g}$ and propofol $140 \mathrm{mg}$. Rocuronium $50 \mathrm{mg}$ was given to facilitate tracheal intubation, and the patient was ventilated with bag and mask for 3 minutes. While manually ventilating the patient, the multichannel monitor displayed a high $\mathrm{EtCO}_{2}$ value $(70-80 \mathrm{~mm} \mathrm{Hg}$, - Fig. 1A). Suspecting this to be due to inadequate mask ventilation, trachea was intubated and ETT position was confirmed by capnography and auscultation. Anesthesia was maintained with sevoflurane in $\mathrm{O}_{2}: \mathrm{N}_{2} \mathrm{O}(40: 60)$ mixture. The $\mathrm{EtCO}_{2}$ value remained high $(90-100 \mathrm{~mm} \mathrm{Hg}$, - Fig. 1B) and kept rising constantly. Despite all measures to decrease $\mathrm{EtCO}_{2}$ including increasing minute ventilation (up to $13 \mathrm{~L} / \mathrm{min}$ ), reconfirming ETT position, increasing fresh gas flow, use of fresh $\mathrm{CO}_{2}$ absorbent,
DOI https://doi.org/ $10.1055 / \mathrm{s}-0039-1679133$ ISSN 2348-0548.
License terms

(ㅇ) (1) $\ominus \circledast$ 

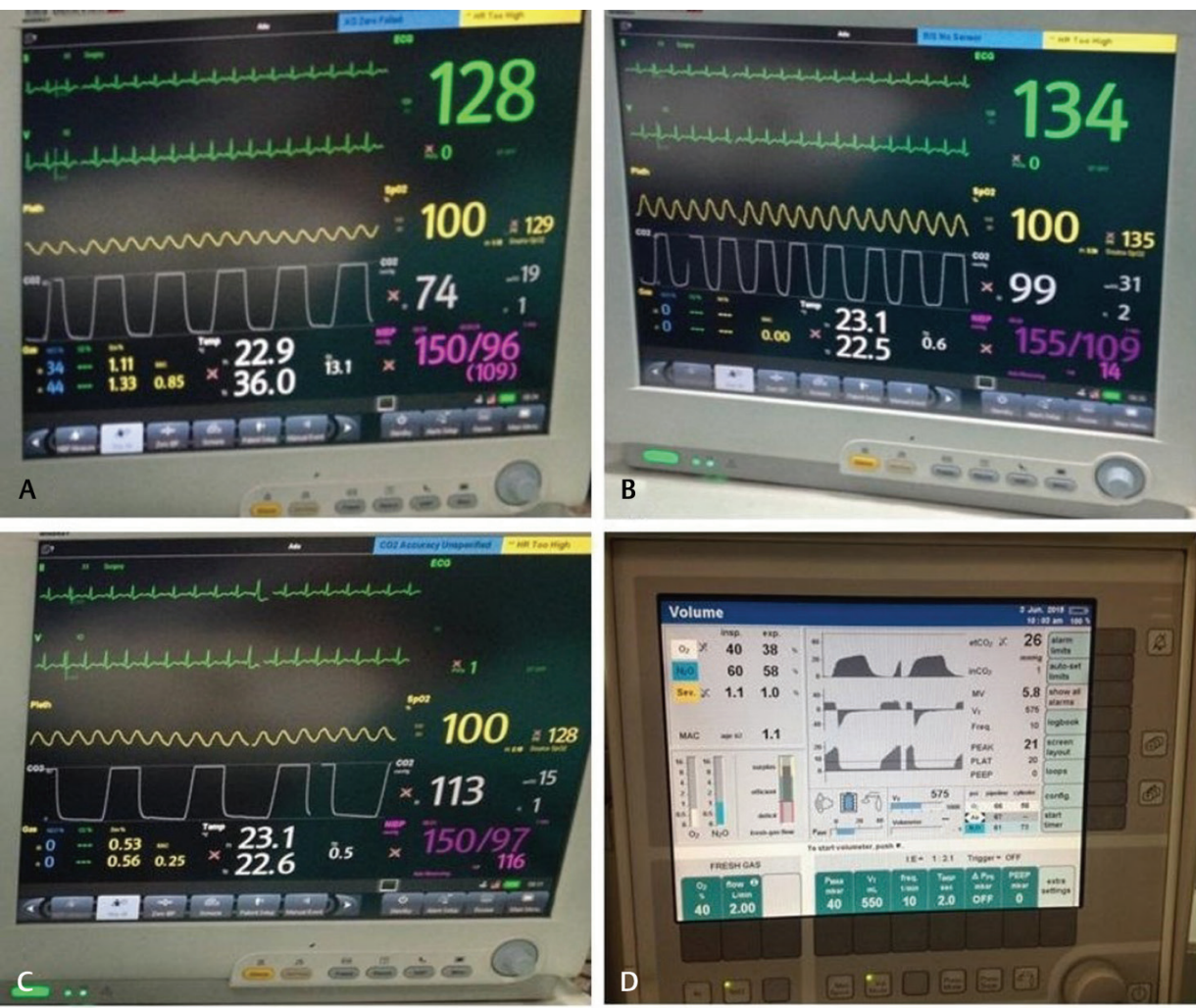

Fig. 1 End-tidal carbon dioxide $\left(\mathrm{EtCO}_{2}\right)$ values displayed over the monitors. (A) Initial high $\mathrm{EtCO}_{2}$ values; $(\mathbf{B}, \mathbf{C})$ gradually increasing EtCO readings despite all efforts to correct it; (D) EtCO, value after changing the monitor.

change of sampling tube and manual ventilation, $\mathrm{EtCO}_{2}$ value kept increasing gradually and reached up to $113 \mathrm{~mm}$ $\mathrm{Hg}$ (-Fig. 1C). An arterial blood gas (ABG) analysis was performed which showed a $\mathrm{PaCO}_{2}$ value of $28 \mathrm{~mm} \mathrm{Hg}$ with all other parameters within normal range, thus, indicating a probability of monitor malfunction and spuriously raised $\mathrm{EtCO}_{2}$. The monitor was then replaced with a new monitor, which showed an $\mathrm{EtCO}_{2}$ value of $26 \mathrm{~mm} \mathrm{Hg}$ with same ventilator settings ( - Fig. 1D).

\section{Discussion}

End-tidal carbon dioxide is the real-time monitoring of exhaled $\mathrm{CO}_{2}$ over time that can be measured using either mainstream or sidestream capnometers with few inherent advantages and disadvantages of each type. $\mathrm{EtCO}_{2}$ is often used as a surrogate for $\mathrm{PaCO}_{2}$ in mechanically ventilated patients. Changes in $\mathrm{EtCO}_{2}$ normally parallel changes in $\mathrm{PaCO}_{2}$. However, there are several clinical situations where $\mathrm{EtCO}_{2}$ values can be raised or decreased.

Sensor windows of mainstream capnometers or sampling line of sidestream capnometers are both prone to clogging by secretions, aerosols, or water droplets. Erroneous $\mathrm{EtCO}_{2}$ readings, such as sudden drop in $\mathrm{EtCO}_{2}$ due to obstruction of sampling tube leading to incorrect interpretation of venous air embolism or large pulmonary embolus, have been reported in literature. ${ }^{4}$ Simple maneuvers, such as purging the sampling line with a syringe to dislodge water droplets in the tubing, replacing the sensor, or sampling tube can correct any artefactual changes in $\mathrm{EtCO}_{2}$ and avoid further unnecessary interventions. At low sampling rates with long sampling catheters, the expired $\mathrm{CO}_{2}$ gas is subjected to axial mixing and dispersion during its transit through the catheter, leading to underestimation of measured $\mathrm{CO}_{2}$ value. ${ }^{5}$ Even a broken Male Luer connector of the sampling tube ${ }^{6}$ and placement of a jet nebulizer between the mainstream capnometer and $\mathrm{ETT}^{7}$ have been reported to cause reduced $\mathrm{EtCO}_{2}$ values.

On the other hand, causes of high $\mathrm{EtCO}_{2}$ can be broadly classified as those due to decreased excretion and due to increased production and iatrogenic causes. ${ }^{8}$ Decreased excretion can be due to increased inspired $\mathrm{CO}_{2}$, decreased ventilation, or increased dead space. Problems with anesthesia machine, such as exhausted soda lime, faulty inspiratory or expiratory valve, and channeling through soda lime can increase inspired $\mathrm{CO}_{2}$ causing high $\mathrm{EtCO}_{2}$. Inadequate ventilation can occur due to leaks in the circuit, bronchospasm, endobronchial intubation, and partial airway obstruction due to kink or mucous plug. Increased production of $\mathrm{CO}_{2}$ due to fever, shivering, convulsions, hyperthyroidism, burns, malignant hyperthermia $(\mathrm{MH})$, and rarely, pheochromocytoma and transfusion reaction can cause high $\mathrm{EtCO}_{2}$. Iatrogenic causes include $\mathrm{CO}_{2}$ insufflation during laparoscopy, tourniquet release, and infusion of sodium bicarbonate. Further, false or spurious increase in $\mathrm{EtCO}_{2}$ can occur due to monitor malfunction or calibration error. In our patient, inspired $\mathrm{CO}_{2}$ values were within normal limits (fractional inspired $\left[\mathrm{FiCO}_{2}\right]$ : 1-2), $\mathrm{CO}_{2}$ absorbent was fresh, and there were no leaks in the circuit. Expiratory unidirectional valve malfunction such as 
valve breakage ${ }^{9}$ or misplaced metal retainer ${ }^{10}$ can result in raised $\mathrm{EtCO}_{2}$ values due to rebreathing of exhaled air and manifest as increase in both inspired and expired segments of $\mathrm{EtCO}_{2}$ waveform. However, in our case inspired $\mathrm{CO}_{2}$ values were always within normal limits. Channeling is difficult to detect but is treated by replacement of soda lime. Hypoventilation was an unlikely cause in our patient as expired tidal volume and blood oxygen saturation were normal. On auscultation, bilateral air entry was equal ruling out endobronchial intubation. Airway pressure was normal, chest was clear, suctioning of the ETT was clear, and there was no delayed upstroke in $\mathrm{EtCO}_{2}$ waveform; so, bronchospasm and partial ETT obstruction seemed unlikely. Our patient's temperature was normal, ruling out fever as a possible cause. It is not possible to detect clinical seizures or shivering in a paralyzed and mechanically ventilated patient. Burns are self-evident; transfusion reaction was not possible in this case since we did not transfuse any blood products. Malignant hyperthermia $(\mathrm{MH})$ was another possibility in our case since we used sevoflurane for maintenance of anesthesia. We did a blood gas analysis to see if $\mathrm{PaCO}_{2}$ values correlated with $\mathrm{EtCO}_{2}$, but it was not increased. The only findings in favor of a diagnosis of $\mathrm{MH}$ were rapidly rising $\mathrm{EtCO}_{2}$ values, use of sevoflurane, and tachycardia. There was no respiratory acidosis on blood gas analysis, $\mathrm{PaCO}_{2}$ was not raised, temperature was normal, and there was no change in urine color; so, $\mathrm{MH}$ was unlikely. A wide difference in $\mathrm{EtCO}_{2}$ and $\mathrm{PaCO}_{2}$ levels in $\mathrm{ABG}$ prompted us to think in terms of spurious increase in $\mathrm{EtCO}_{2}$. We changed the monitor. The new monitor showed $\mathrm{EtCO}_{2}$ value of $26 \mathrm{~mm}$ $\mathrm{Hg}$, thus, confirming that the cause of high $\mathrm{EtCO}_{2}$ in this case was a fault with the monitor.

In healthy subjects, $\mathrm{EtCO}_{2}$ and $\mathrm{PaCO}_{2}$ generally correlate well. $\mathrm{PaCO}_{2}$ values are generally 2 to $5 \mathrm{~mm} \mathrm{Hg}$ above $\mathrm{EtCO}_{2}$ values. However, in conditions of increased physiological dead space, the correlation between end-tidal and arterial $\mathrm{CO}_{2}$ is poor. With increased physiological dead space, there is mixing of gas from poorly perfused areas of lung with that from well-perfused areas, resulting in a lower $\mathrm{EtCO}_{2}$ relative to $\mathrm{PaCO}_{2} \cdot{ }^{11}$ In our case, though the gradient was widened, the change was in the reverse direction, $\mathrm{EtCO}_{2}$ being much higher relative to $\mathrm{PaCO}_{2}$. An increase in physiological dead space could not have explained this discrepancy. A fault with the monitor or a calibration error was the only possible cause.

The manufacturing company of the monitor was contacted to detect and rectify the fault in the monitor. The service engineers tested and recalibrated the equipment. However, discussion with service engineer did not yield anything specific. Subsequent use of the monitor after recalibration displayed correct $\mathrm{EtCO}_{2}$ values, which correlated with $\mathrm{PaCO}_{2}$ values.

\section{Conclusion}

Our case highlights that monitor malfunction per se may sometimes result in fallacious $\mathrm{EtCO}_{2}$ readings and it should always be seen as a possibility if no other cause is found before undertaking extensive interventions. It re-emphasizes the fact that various monitors used under anesthesia must always be interpreted in correlation with clinical observation.

\section{Conflict of Interest}

None declared.

\section{References}

1 Donald MJ, Paterson B. End tidal carbon dioxide monitoring in prehospital and retrieval medicine: a review. Emerg Med J 2006;23(9):728-730

2 Razi E, Moosavi GA, Omidi K, Khakpour Saebi A, Razi A. Correlation of end-tidal carbon dioxide with arterial carbon dioxide in mechanically ventilated patients. Arch Trauma Res 2012;1(2):58-62

3 Russell GB, Graybeal JM. The arterial to end-tidal carbon dioxide difference in neurosurgical patients during craniotomy. Anesth Analg 1995;81(4):806-810

4 Vinay B, Sriganesh K, Gopala Krishna KN. An abrupt reduction in end-tidal carbon-dioxide during neurosurgery is not always due to venous air embolism: a capnograph artefact. J Clin Monit Comput 2014;28(2):217-219

5 Breen PH, Mazumdar B, Skinner SC. Capnometer transport delay: measurement and clinical implications. Anesth Analg 1994;78(3):584-586

6 Soumya M, Vimala S, Arulvelan A. Acute reduction in the end-tidal carbon dioxide level during neurosurgery: another cause for capnography artefact. J Neurosurg Anesthesiol 2017;29(3):365-366

7 Vinay B. An abrupt reduction in end tidal carbon di oxide concentration in a mechanically ventilated patient in neurocritical care ward: a capnogram artifact. J Clin Monit Comput 2018;32(2):369-371

8 Tautz TJ, Urwyler A, Antognini JF, Riou B. Case scenario: increased end-tidal carbon dioxide: a diagnostic dilemma. Anesthesiology 2010;112(2):440-446

9 Lee C, Lee KC, Kim HY, et al. Unidirectional valve malfunction by the breakage or malposition of disc - two cases report. Korean J Anesthesiol 2013;65(4):337-340

10 Kumar A, Bithal P, Chouhan RS, Sinha PK. Should one rely on capnometry when a capnogram is not seen? J Neurosurg Anesthesiol 2002;14(2):153-156

11 McSwain SD, Hamel DS, Smith PB, et al. End-tidal and arterial carbon dioxide measurements correlate across all levels of physiologic dead space. Respir Care 2010;55(3):288-293 